\title{
Direct Borylation of Arenes Catalyzed by $\gamma-\mathrm{Fe}_{2} \mathrm{O}_{3}$
}

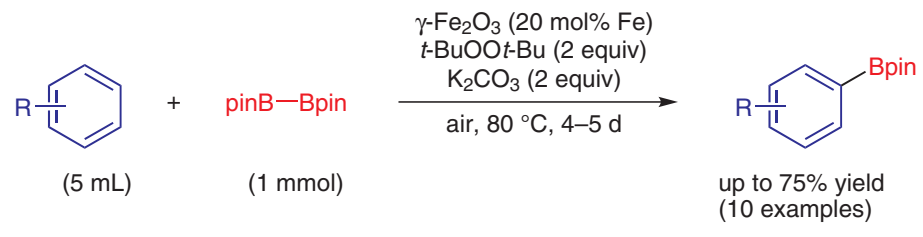

Key words

maghemite

direct borylation

arenes

bis(pinacolato)-

diborane
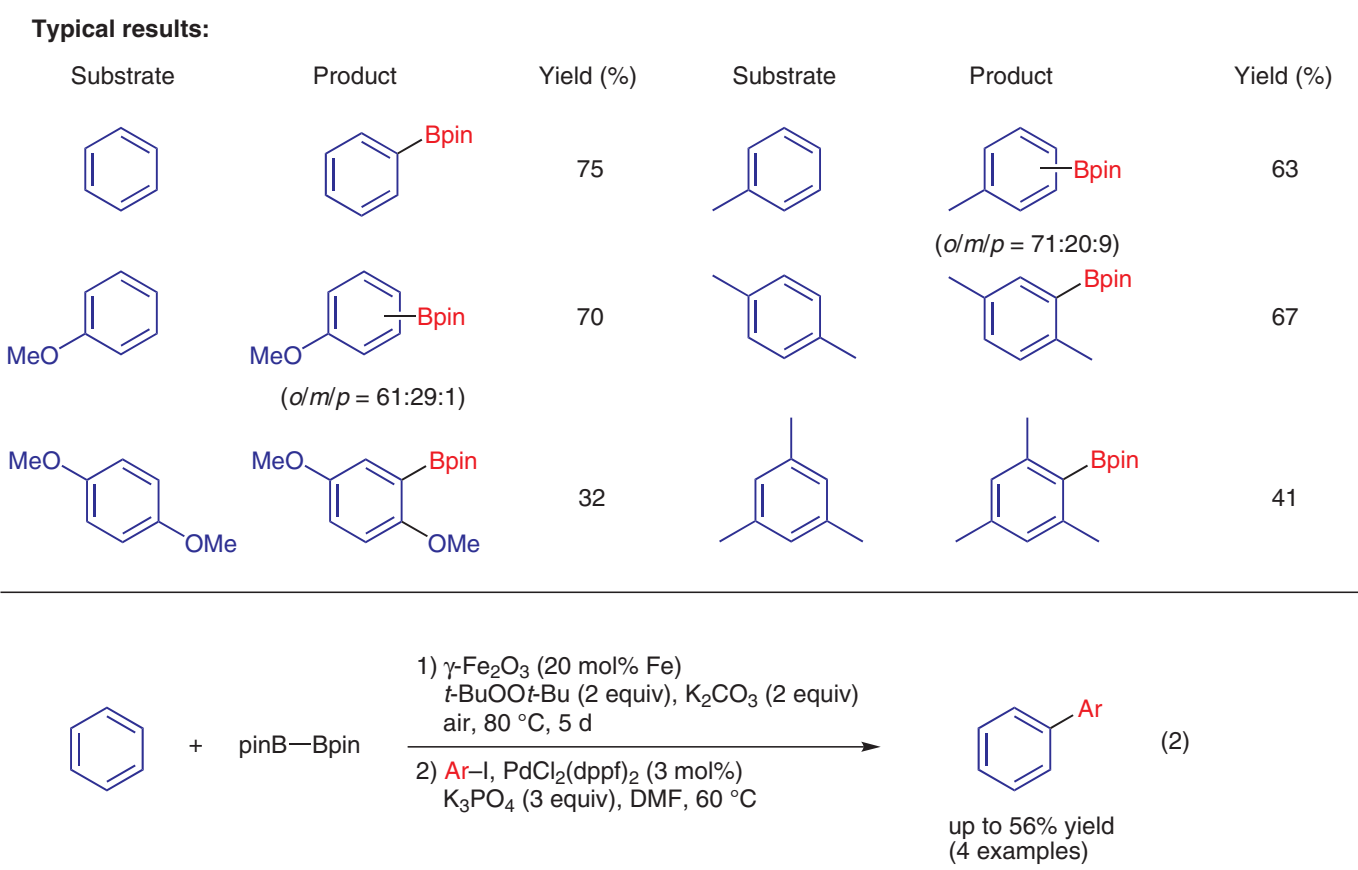

$\mathrm{Ar}=4-\mathrm{O}_{2} \mathrm{NC}_{6} \mathrm{H}_{4}, 4-\mathrm{MeOC}_{6} \mathrm{H}_{4}, 4-\mathrm{ClC}_{6} \mathrm{H}_{4}, 4-\mathrm{MeC}(\mathrm{O}) \mathrm{C}_{6} \mathrm{H}_{4}$

Significance: $\gamma-\mathrm{Fe}_{2} \mathrm{O}_{3}$ magnetic nanoparticles (particle size $58 \mathrm{~nm}$ ) catalyzed the borylation of arenes with bis(pinacolato)diborane in the presence of di-tert-butyl peroxide and potassium carbonate under air to give the corresponding borylated products in up to $75 \%$ yield (10 examples, eq. 1). A sequential reaction via $\gamma-\mathrm{Fe}_{2} \mathrm{O}_{3}$-catalyzed borylation of benzene and Suzuki-Miyaura coupling with iodoarenes gave the corresponding biaryls in up to $56 \%$ yield (4 examples, eq. 2).
Comment: The catalytic activity of $\gamma-\mathrm{Fe}_{2} \mathrm{O}_{3}$ was superior to that of the other iron catalysts, such as $\mathrm{FeCl}_{3}, \mathrm{FeBr}_{3}, \mathrm{FeF}_{3}, \mathrm{Fe}(\mathrm{acac})_{3}, \mathrm{Fe}_{2}\left(\mathrm{SO}_{4}\right)_{3}$, and $\mathrm{Fe}_{2} \mathrm{O}_{3}$. In the borylation of toluene and anisole, the ortho-borylated products were obtained as major regioisomers. 